\title{
Effect of different cold storage periods of rearing host eggs on the performance of the parasitoid Trichogramma evanescens (Westwood) (Hymenoptera: Trichogrammatidae)
}

\author{
Amany Siam ${ }^{1 *}$, Nawal Zohdy Mohammed Zohdy ${ }^{2}$, Alia Mohammed Abd ELHafez ${ }^{3}$, Laila Eid Moursy ${ }^{2}$ and \\ Hanaa Ahmed E. L. Sherif ${ }^{2}$
}

\begin{abstract}
Laboratory experiments were carried out to evaluate the acceptance of Trichogramma evanescens (Westwood) (Hymenoptera: Trichogrammatidae) to long and short cold storage periods of the host, the Angoumois grain moth, Sitotroga cerealella Olivier (Lepidoptera: Gelechiidae) eggs. The eggs were stored at $5^{\circ} \mathrm{C}$ for $5,10,15,20$, and 30 days, before exposing to the parasitoid. Fecundity, longevity, percentage of adult emergence, sex ratio, and general productivity (GP) were investigated. Storage period to 5 days showed the highest productivity of ( 28.16 females), with a parasitism efficiency of $85.64 \%$. Increasing storage periods to 10,15 , and 20 days reduced the general productivity of the females to $22.90,15.00$, and 7.75 females, respectively, accompanied by decreased parasitization efficacy values $69.65,46.62$, and $23.57 \%$, respectively. The 30-day storage period decreased sharply the fitness components of Trichogramma females. Generally, the results indicated that the storage period to 5 days was the most favorable.
\end{abstract}

Keywords: Trichogramma evanescens, Sitotroga cerealella, Cold storage, Parasitized eggs, Parasitoid performance

\section{Background}

Cold storage of rearing host eggs received more attention in recent years because of its importance in the field of biological control (Huang et al. 2017). It assures its availability in sufficient numbers at the time of release, providing flexibility and efficiency in mass production (Gosh and Ballal 2017). It is used to slow development, to facilitate organisms, and to accommodate fluctuating demand for augmentative biological control agents (Gardner et al. 2012). Trichogramma evanescens (Westwood) (Hymenoptera: Trichogrammatidae) is a true egg parasitoid species, widely used in inoculative and augmentative release programs to regulate pest populations, mainly lepidopterous ones (Smith 1996). It shows a vital role in destroying the early stages of the

\footnotetext{
*Correspondence: amanysiam200@gmail.com

'Department of Agricultural Harmful Animals, ARC, P. O. Box 12311, Orman, Giza, Egypt

Full list of author information is available at the end of the article
}

pest; the eggs. The Angoumois grain moth, Sitotroga cerealella Olivier (Lepidoptera: Gelechiidae), is mainly considered one of the major and commercial rearing hosts of Trichogramma parasitoids in laboratory (Hassan 1995). Cold storage of the host eggs that will be exposed to the parasitoid after its storage for different periods may have an impact on the efficiency of Trichogramma parasitoids. (Bradely et al. 2004) and the elongation of cold storage may affect the survival of the resulting parasitoids with a remarkable reduction in the efficiency of produced females (Ozder 2004).

The aim of this work was to select a suitable cold storage durations of Sitotroga host eggs that affect positively the performance of the resulting Trichogramma.

\section{Materials and methods}

This work was conducted at Fayoum Laboratory of Trichogramma Mass Rearing, Plant Protection Research Institute, Agricultural Research Center, Egypt. Rearing of 
egg parasitoids, Trichogramma, required the host eggs prepared on cards by a thin layer of ordinary glue to produce eggs in which the parasitoids will develop. Rearing moths and parasitoids were conducted at the laboratory conditions at $25 \pm 2{ }^{\circ} \mathrm{C}$ and $75 \pm 5 \% \mathrm{RH}$. The tested host eggs were stored in an incubator at $5{ }^{\circ} \mathrm{C}$.

\section{Rearing of Sitotroga cerealella}

Sitotroga cerealella Olivier (Lepidoptera: Gelechiidae) was reared according to the techniques modified by Laing and Eden (1990) and Hassan (1995).

\section{Rearing of Trichogramma evanescens}

$T$. evanescens was mass reared using $S$. cerealella eggs as described by Abd EL Hafez (1995), where the host eggs $(<24 \mathrm{~h}$ old $)$ were placed on self-adhesive paper cards of $21 \times 15 \mathrm{~cm}$, then exposed to the parasitoids in glass jars (2 1 capacity) provided with drops of sugar cane honey for nutrition. The jars were covered by cloth-wrapped cotton and fixed in position by rubber bands. Egg cards were renewed daily to avoid super-parasitism.

\section{Experimental technique}

Eggs of Sitotroga were stored in an incubator at $5{ }^{\circ} \mathrm{C}$, according to Filho et al. (2014) for 5, 10, 15, 20, and 30 days. Fresh eggs were used as control. Twenty-five replicates were carried out per treatment. Stored eggs were tested immediately after each cold storage period by exposing them to separated and mated females under the laboratory conditions. Fifty $S$. cerealella eggs of both cold stored and control were placed on self-adhesive paper cards, each in a test tube $(4 \times 8.5 \mathrm{~cm})$ before exposing to a separated, mated Trichogramma female. A drop of sugar cane honey was provided as food placed on the inner side of each tube. The egg cards were replaced daily until the parasitoid females died. Parasitized eggs were kept in clean vials under the same rearing conditions. The number of parasitized eggs (blackened host eggs) was counted and recorded as fecundity of females in each treatment. The percentage of emerged adults was calculated as the number of emerged adults vs. the number of parasitized eggs $\times 100$. Female's ratio was estimated as the number of produced females vs. number of individuals' $\times 100$.

The general productivity (GP) was calculated as GP $=$ rate of emergence $\times$ rate of produced females in progeny $\times \mathrm{fe}$ cundity (Tshernyshev and Afonina 1995). The parasitization efficiency (PE) as one of the main parameters in evaluating female's performance was considered as the rate of general productivity in relation to control. The reduction in PE was estimated for each treatment.

\section{Statistical analysis}

The statistical analysis of variance program, ANOVA, was used. Duncan's multiple range test (Duncan 1955) was used to separate means (Snedecor and Cochran 1980).

\section{Results and discussion \\ Effect of different cold storage periods of S. cerealella eggs on the efficacy of $T$. evanescens}

Data in Table 1 shows that the parasitization on the non-cold-stored host eggs (control) were higher than any of the cold stored ones. Statistically, cold storage of host eggs had a significant effect on the acceptance of Trichogramma females $(P<0.05)$. Considering 5 days stored eggs, the percentage of parasitization decreased from 96.44 to $90.08 \%$. All the cold storage periods significantly affected also the adult emergence $(P<0.05)$. In the control, the percentage of parasitoid emergence attained $96.92 \%$, while it was $94.85 \%$ for the 5 days' storage at $5{ }^{\circ} \mathrm{C}$. The other cold storage periods $(10,15,20$, and 30 days) resulted in the adult emergence percentages of $84.91,80.48,61.17$, and $50.73 \%$, respectively (Table 1 ).

Cold storage periods significantly affected the percentage of produced females in progeny. It averaged $70.04 \%$. This percent decreased to $48.46 \%$ in case of the eggs stored for 30 days (Table 1 ).

Longevity of females declined significantly with increasing the duration of the host eggs cold storage $(P<0.05)$. The females produced from 5 -day cold-stored eggs at $5{ }^{\circ} \mathrm{C}$ lived nearly as that of the control, but they differed insignificantly from those produced from 10-day coldstored host eggs. Female emergence rates from the cold-stored host eggs for 15, 20, and 30 days showed shorter life span with the means of $3.44,2.8$, and 2.48 days, respectively (Table 1 ).

\section{Effect of different cold storage periods on productivity of T. evanescens}

Cold storage of the host eggs caused a reduction in the biological parameters of the produced parasitoid adults, represented in the fecundity, adult emergence percentage, and ratio of females. These parameters were conflicted on the general productivity (GP) of the produced females, which was reduced from 32.88 females at the control group to only 2.51 females in case of 30 days storage group. This result conflicted the parasitization efficacy (PE), which was reduced from $85.64 \%$ at the group of 5-day storage to $7.63 \%$ at the 30 days stored group. Accordingly, the PE reduction reached 14.36 and $92.37 \%$, at 5 and 30 days cold storage groups, respectively (Table 2 ).

The present work indicated that cold storage can help in extending the availability of Trichogramma in sufficient numbers, which is desired in mass production leading to the efficiency in field release applications. 
Table 1 Effect of using cold-stored S. cerealella eggs on the efficacy of Trichogramma evanescens

\begin{tabular}{llllll}
\hline Cold storage periods & Number of parasitized eggs/female & \% parasitism & \% emergence & \% females & Female longevity (days) \\
\hline Control & $48.44 \pm 0.58^{\mathrm{a}}$ & $96.44 \pm 5.08^{\mathrm{a}}$ & $96.92 \pm 6.47^{\mathrm{a}}$ & $70.04 \pm 1.68^{\mathrm{a}}$ & $4.36 \pm 0.64^{\mathrm{a}}$ \\
5 days & $45.04 \pm 0.95^{\mathrm{b}}$ & $90.08 \pm 0.87^{\mathrm{b}}$ & $94.85 \pm 2.19^{\mathrm{a}}$ & $65.91 \pm 0.66^{\mathrm{b}}$ & $4.04 \pm 0.68^{\mathrm{ab}}$ \\
10 days & $42.86 \pm 4.33^{\mathrm{c}}$ & $85.72 \pm 1.11^{\mathrm{c}}$ & $84.91 \pm 5.03^{\mathrm{c}}$ & $62.92 \pm 0.89^{\mathrm{c}}$ & $3.84 \pm 0.68^{\mathrm{b}}$ \\
15 days & $30.62 \pm 1.27^{\mathrm{d}}$ & $61.24 \pm 1.51^{\mathrm{d}}$ & $80.48 \pm 0.66^{\mathrm{d}}$ & $60.85 \pm 1.21^{\mathrm{d}}$ & $3.44 \pm 0.69^{\mathrm{c}}$ \\
20 days & $24.54 \pm 1.44^{\mathrm{e}}$ & $49.08 \pm 2.03^{\mathrm{e}}$ & $61.17 \pm 1.54 \mathrm{e}$ & $51.64 \pm 2.50^{\mathrm{e}}$ & $2.8 \pm 0.51^{\mathrm{d}}$ \\
30 days & $10.22 \pm 4.65^{\mathrm{f}}$ & $20.44 \pm 1.47^{\mathrm{f}}$ & $50.73 \pm 4.17^{\mathrm{f}}$ & $48.46 \pm 7.16^{\mathrm{f}}$ & $2.48 \pm 0.41^{\mathrm{d}}$
\end{tabular}

Means followed by the same letter, in the same column, are not significantly different. (Duncan's multiple range tests) (Duncan 1955)

Obtained results are in constancy with those of Gardner et al. (2012) who reported that cold storage of bio agents could help in reducing costs of production by allowing discontinuous production schedules. Also, Gosh and Ballal (2017) reported that the host egg storage, with different techniques, would be beneficial for laboratories to stock host eggs leading to continuous production of Trichogramma for field release. Obtained results revealed that cold storage of $S$. cerealella eggs at $5{ }^{\circ} \mathrm{C}$ for 5 up to 10 days had no severe effects on the fitness components of $T$. evanescens females, as the period of 5 days was nearly similar to the control results, followed by the 10-day cold storage period. On the other hand, exposure of the Sitotroga eggs to low temperatures for long durations up to 30 days showed a reduction in all biological parameters.

The results of Gerco and Stilinovic (1998) agree with the present work data as they advised that the suitable cold storage periods for $S$. cerealella eggs must not extend past 35 days. In addition, using different species of the host eggs or different methods of the host egg preservation, the storage duration up to 30 days adversely influenced adult emergence percentage, fecundity and the produced female's ratio in progeny EL Khayat et al. (2001) who worked on Pectinophora gossypiella (Saunds.) eggs, and Tuncbilek et al. (2009) who worked on Ephestia kuehniella (Zeller). The present results varied than other works conducted on different species of Trichogramma and different factitious hosts as Paulo et al. (2014) who evaluated the suitability of Anagasta (Ephestia) kuehniella eggs

Table 2 General productivity (GP), parasitization efficiency (PE), and reduction in parasitization efficiency (RPE) of Trichogramma evanescens reared on Sitotroga cerealella eggs stored at $5{ }^{\circ} \mathrm{C}$ for different periods

\begin{tabular}{llll}
\hline Cold storage periods (days) & GP & PE & RPE \\
\hline Control & 32.88 & - & - \\
5 & 28.16 & 85.64 & 14.36 \\
10 & 22.90 & 69.65 & 30.35 \\
15 & 15.00 & 46.62 & 53.38 \\
20 & 7.75 & 23.57 & 76.43 \\
30 & 2.51 & 7.63 & 92.37 \\
\hline
\end{tabular}

stored at $5^{\circ} \mathrm{C}$ as a host for Trichogrammatoidea annulata, T. galloi, T. cacacioi, T. atopovirilia, T. benneti, T. brasiliensis, T. bruni, T. demoraesi, T. pretiosum, and T. soaresi at different storage periods from 5 days up to 40 days. They mentioned that all the species varied in their parasitism up to 24 days, except $T$. acacioi, which parasitized the cold host eggs for longer periods showing the highest parasitism and adult emergence. Also, Karaborklu and Ayvaz (2007) reported that emergence, parasitism, and longevity of $T$. evanescens adults emerged from stored host eggs decreased depending on the storage periods at $4{ }^{\circ} \mathrm{C}$; however, sex ratio of adults was not affected by storage temperature and periods. The results of $\mathrm{Wu}$ et al. (2018) revealed that the survival rates of T. chilonis immatures decreased significantly when Corcyra cephalonica eggs were cold stored for more than 15 days.

The present results revealed that the general productivity of females decreased from 32.88 females at the control group to 28.16 females at the 5 days group and then it decreased drastically to 2.51 females at 30 days group. This may be due to the low temperatures that reduce host eggs vitality. Corresponding results of Kostal et al. (2004) reported that rearing the parasitoids on coldstored host eggs usually reduces their performance as long as the exposure to the low temperature and reduces the host eggs quality and vitality. Also, Huang et al. (2017) stated that cold storage of the host eggs was very important to meet the need of Trichogramma mass rearing, but the elongation of such periods caused changes in the chemical components of C. cephalonica eggs, which affected the growth and development of Trichogramma parasitoids.

\section{Conclusion}

The obtained results revealed that the cold storage of the $S$. cerealella eggs for 5 days was the suitable duration for sustainable production of high-quality Trichogramma parasitoid individuals, and it is recommended to store $S$. cerealella eggs at $5{ }^{\circ} \mathrm{C}$ for not more than 10 days. 


\section{Funding}

No fund.

\section{Availability of data and materials}

The data and materials of this study have been presented in the manuscript.

\section{Authors' contributions}

The authors cooperated in all the experiments, statistical analysis of data, reading, and approval of the final manuscript.

\section{Ethics approval and consent to participate}

Not applicable.

\section{Consent for publication}

Not applicable.

\section{Competing interests}

The authors declare that they have no competing interests.

\section{Publisher's Note}

Springer Nature remains neutral with regard to jurisdictional claims in published maps and institutional affiliations.

\section{Author details}

'Department of Agricultural Harmful Animals, ARC, P. O. Box 12311, Orman, Giza, Egypt. ${ }^{2}$ Faculty of Science, Entomology Department, Cairo University,

Giza, Egypt. ${ }^{3}$ Plant Protection Research Institute, ARC, Dokki, Giza, Egypt.

Received: 2 March 2019 Accepted: 13 May 2019

Published online: 24 May 2019

\section{References}

Abd EL Hafez A (1995) A comparison of thermal requirements and some biological aspects of Trichogramma evanescens (Westwood) and Trichogrammatoidea bactrae (Najgaja) reared from eggs of the pink and spiny bollworm. Ann Agric Sci Ain Shams Univ Cairo 4(2):901-912

Bradely JR, Thomson L, Hoffmann AA (2004) Effect of cold storage on field and laboratory performance of Trichogramma carverae (Hymenoptera: Trichogrammatidae) and the response of three Trichogramma spp. (Trichogramma carverae, Trichogramma nr. Brassicae and Trichogramma funiculatum) to cold. J Econ Entomol 97:213-221

Duncan DB (1955) Multiple range and multiple F tests. Biometrics 11:1-41

El Khayat EF, Abd El Hafez A, Shalaby FF, El Sharkawy MA (2001) Cold storage of Pectinophora gossypiella (Saund.) eggs parasitized by Trichogramma and effect on some biological parameters. Egypt J Agric Res 79(1):133-147

Filho SRP, Leite GLD, Soares MA, Alvarenga AC, Paulo PD, Santos LDT, Zanuncio JC (2014) Effects of duration of cold storage of host eggs on percent parasitism and adult emergence of ten trichogrammatidae species. Fla Entomol 97(1):14-21

Gardner J, Hoffmann MP, Pitcher SA, Nyrop JP (2012) Recurrent warming to improve cold storage of trichogrammatids (Hym.: Trichogrammatidae). Biocont Sci Tech 22(3):261-270

Gerco CF, Stilinovic D (1998) Parasitization performance of Trichogramma spp. (Hym.: Trichogrammatidae) reared on eggs of Sitotroga cerealella Oliver (Lep.: Gelechiidae) stored at freezing and subfreezing conditions. J Appl Entomol 122(6):311-314

Gosh E, Ballal CR (2017) Effect of age dependent cold storage of factitious host Corcyra cephalonica (Stainton) (Lepidoptera: Pyralidae) for their continuous production and Trichogramma chilonis (Ishii) (Hymenoptera: Trichogrammatidae) rearing. J Asia Pac Entomol 20(3):928-934

Hassan SA (1995) Improved method for the production of the Angoumois grain moth Sitotroga cerealella Oliv. Trichogramma and other egg parasitoids conference. Cairo, Egypt, vol 1994. Ed IUNRA, Paris, pp 157-160

Huang Y, Han W, Song ZW, Song D, Zhang GR (2017) Effect of cold storage on the chemical composition of Corcyra cephalonica eggs by HNUR spectroscopy. Biol Control 110:25-32

Karaborklu S, Ayvaz A (2007) Effects of cold storage on the life stages of Trichogramma evanescens Westwood (Hym.: Trichogrammatidae) reared on different host eggs. Erciyes Uiversitesi Fen Bilimleri Enstitusu Dergisi 23(2):30-36
Kostal V, Vambera J, Bastl J (2004) On the nature of pre-freeze mortality in insects, water balance, ion homeostasis and energy charge in the adults of Pyrrhocoris apterus. J Exp Biol 207:1509-1521

Laing JE, Eden V (1990) Mass production of Trichogramma minutum Riley on factitious host eggs. Mem Ent Soc Can 153(2):10-24

Ozder N (2004) Effect of different cold storage periods on parasitization performance of Trichogramma cacoeciae (Hymenoptera: Trichogrammatidae) on eggs of Ephestia kuehniella (Lepidoptera: Pyralidae). Biocontrol Sci Tech 14(5):444-447

Paulo RF, Germano LD, Soares MA, Costa A, Paulo PD, David L, Zanuncio JC (2014) Effects of duration of cold storage of host eggs on percent parasitism and adult emergence of each of ten Trichogrammatidae species. Fla Entomol 97(1):14-21

Smith SM (1996) Biological control with Trichogramma: advances, success and potential of their use. Ann Rev Entomol 41(2):375-406

Snedecor GW, Cochran GW (1980) Statistical methods, 7th edn. lowa State University Press, Ames

Tshernyshev WB, Afonina VM (1995) Optimal light and temperature conditions for Trichogramma evanescens Westwood rearing. In: Trichogramma and other Egg Parasitoids, Fourth International Symposium Cairo, Egypt, 4-7 October 1994. INRA Publ, Paris, pp 173-175

Tuncbilek AS, Canpolat U, Sumer F (2009) Suitability of irradiated and cold stored eggs of Ephestia kuehniella (Lep.: Pyralidae) and Sitotroga cerealella (Lep: Gelechidae) for stockpiling the egg parasitoid Trichogramma evanescens (Hym.: Trichogrammatidae) in diapause. Biocontrol Sci Tech 19(2):127-138

Wu H, Huang Y, Guo J, Liu JB, Zhang G (2018) Effect of cold storage of Corcyra cephalonica on the fitness for Trichogramma chilonis. Biol Control 124:40-45

\section{Submit your manuscript to a SpringerOpen ${ }^{\circ}$ journal and benefit from:}

- Convenient online submission

- Rigorous peer review

- Open access: articles freely available online

High visibility within the field

- Retaining the copyright to your article

Submit your next manuscript at $\boldsymbol{\nabla}$ springeropen.com 